\title{
A biocompatible hybrid material with simultaneous calcium and strontium release capability
}

J. Carlos Almeidaa, András Wacha ${ }^{b}$, Pedro S. Gomes ${ }^{c}$, Luís C. Alves ${ }^{d}$, M. Helena Vaz Fernandes ${ }^{a}$, Isabel M. Miranda Salvado ${ }^{a,{ }^{*}}$, M. Helena R. Fernandes ${ }^{c}$

${ }^{a}$ CICECO - Aveiro Institute of Materials, Department of Materials and Ceramic Engineering, University of Aveiro, 3810193 Aveiro, Portugal

${ }^{b}$ Research Centre for Natural Sciences, Hungarian Academy of Sciences, Magyar Tudósok körútja 2, Budapest, 1117 Hungary

'Laboratory for Bone Metabolism and Regeneration, Faculdade de Medicina Dentária, Universidade do Porto, Portugal ${ }^{d}$ C2TN, Instituto Superior Técnico, Universidade de Lisboa, E.N.10, 2695-066,Bobadela LRS, Portugal

* Corresponding author at: Tel.: +351 234370354; fax: +351 234370204; E-mail address: isabelmsalvado@ua.pt

Keywords: biocompatible, hybrid materials, strontium

\section{Abstract}

The increasing interest in the effect of strontium in bone tissue repair has promoted the development of bioactive materials with strontium release capability. In fact, the incorporation of strontium in bioactive glasses, for example, has been studied extensively. According to literature, hybrid materials have been considered a plausible alternative as they present a mechanical behavior similar to the one of the human bone. The main purpose of this study was to obtain a biocompatible hybrid material with simultaneous calcium and strontium release capability. A hybrid material, in the system $\mathrm{PDMS}^{-\mathrm{SiO}_{2}-\mathrm{CaO}-}$ $\mathrm{SrO}$, was prepared with the incorporation of titanium. Calcium and strontium were added using the respective acetates as sources, following a sol-gel technique previously developed by the present authors. The obtained samples were characterized by FT-IR, solid-state NMR, SAXS, and surface roughness was analyzed by 3D optical profilometry. In vitro studies were performed by immersion of the samples in Kokubo's SBF for different periods of time, in order to determine the bioactive potential of these hybrids. Surfaces of the immersed samples were observed by SEM, EDS and PIXE, showing the formation of calcium phosphate precipitates. Supernatants were analyzed by ICP, revealing the capability of the material to simultaneously fix phosphorus ions and to release calcium and strontium, in a concentration range within the values 
reported as suitable for the induction of the bone tissue repair. The material demonstrated to be cytocompatible when tested with MG63 osteoblastic cells, exhibiting an inductive effect on cell proliferation and alkaline phosphatase activity.

\section{Introduction}

Hybrid materials have the advantage of possessing properties that go beyond the simple sum of its organic and inorganic contributions [1]. A documented example is the combination of the mechanical properties of non-bioactive silicone (polidimethylsiloxane - PDMS), with the ability to bind to hard tissues of bioglasses' [2,3], in an attempt to develop new materials to treat bone injuries/defects. The sol-gel processing at low temperatures of these hybrids is easy and has the capability to achieve monolithic parts. However it inhibits the use of precursors that require a firing/decomposition step to eliminate potentially toxic residues. During years this was a problem when dealing with the incorporation of calcium, an element of bioglass compositions associated to the biocompatibility. Calcium has been usually added to the sol-gel process using its nitrate form with a decomposition temperature higher than the degradation temperature of PDMS [4]. Since this problem was solved with the use of calcium acetate as a precursor [5], new possibilities opened.

With respect to the bone tissue repair, it is known that the bone formation/resorption equilibrium is affected by a variety of physical/chemical agents and processes such as inorganic ions, growth factors, hormones and stress actions [6].

The knowledge acquired regarding the role of metal ions, such as calcium, phosphorous, silicon, strontium, zinc, etc., in the stimulation of metabolic effects that occurs during tissue formation has shown the usefulness of these ions as therapeutic agents, after being incorporated in the composition of new biomaterials [4].

Strontium has demonstrated in vitro stimulatory effect on osteoblasts together with an inhibitory effect on osteoclasts [7-9], and the ability to substitute calcium in the hydroxyapatite crystal lattice $[8,10]$. It has also been incorporated in the 
structure of new bioactive materials [11], and is used as a drug in the form of strontium ranelate to increase the densification of bone in osteoporotic patients [12]. Pharmacological studies about strontium ranelate reveal that it increases the alkaline phosphatase activity (a marker of osteoblast differentiation) in osteoblast precursor cells and in mature osteoblastic cells, and collagen synthesis (a marker of osteoblast function) [13]. In vivo studies of Sr-bioactive glasses [14] have shown that strontium has a dual function within bone remodeling. It is able to uncouple the process of bone resorption and bone formation by inhibiting osteoclasts and stimulating osteoblasts, respectively, leading to a gain in bone mass. Such findings heightened the need for the development of new bioactive materials with strontium release capability.

In the present work a hybrid material, in the system $\mathrm{PDMS}-\mathrm{SiO}_{2}-\mathrm{TiO}_{2}-\mathrm{CaO}-\mathrm{SrO}$, was prepared. As far as it is known it is the first time that a sol-gel protocol is designed to add both calcium and strontium to the $\mathrm{PDMS}^{-\mathrm{SiO}_{2}}$ hybrid system and its cytocompatibility is evaluated. Based on authors' previous findings the addition of titanium is justified by its capability to condition the sol-gel chemistry of the system $\mathrm{PDMS}-\mathrm{SiO}_{2}$, allowing the modulation of the final microstructure, besides the fact that titanium can also increase the bioactivity, due to surface Ti-OH groups [15]. To avoid the use of nitrates, calcium and strontium were added using the respective acetates as sources, according to a sol-gel technique already described in a previous work [5]. The materials' structures and microstructures were analyzed by Fourier Transform Infrared Spectrometry (FT-IR), solid state Nuclear Magnetic Resonance (NMR) techniques, Smallangle X-ray Scattering (SAXS) and Scanning Electron Microscopy (SEM). Surface roughness was analyzed by $3 \mathrm{D}$ optical profilometry. In vitro studies were performed by immersion of the samples in Kokubo's SBF for different periods of time, in order to determine in a first approach the bioactive potential of these hybrids and the material capability to release strontium. Surfaces of the immersed samples were observed by SEM and analyzed by Electron Dispersive Spectroscopy (EDS) and Particle Induced X-ray Emission (PIXE). Supernatants were analyzed by Inductively Coupled Plasma spectroscopy (ICP). Cytocompatibility was assessed for the response of MG63 osteoblastic 
cells characterized for cell proliferation, alkaline phosphatase activity, and observation by SEM.

\section{Materials and methods}

\subsection{Sample preparation}

Tetraethyl orthosilicate (TEOS), polydimethylsiloxane (PDMS) silanol terminated (550 g mol${ }^{-1}$ average molecular weight), isopropanol (IPA), calcium acetate monohydrate $\left(\mathrm{Ca}\left(\mathrm{CH}_{3} \mathrm{CO}_{2}\right)_{2} \cdot \mathrm{H}_{2} \mathrm{O}\right)$, strontium acetate $\left(\mathrm{Sr}\left(\mathrm{CH}_{3} \mathrm{CO}_{2}\right)_{2}\right)$, titanium isopropoxide ( $\mathrm{TiPr}$ ), all from Sigma-Aldrich, and ethyl acetoacetate (EtAcAc) from Merck, were used as raw materials for the preparation of the hybrids. Samples were prepared using a 1:0.05:0.05:0.18:0.05:5:0.22 TEOS/Ca-acetate/Sr-acetate/PDMS/TiPr/ $\mathrm{H}_{2} \mathrm{O} / \mathrm{HCl}$ molar ratios. The procedure was already described in a previous work [5]: separate aqueous solutions of $\mathrm{Ca}\left(\mathrm{CH}_{3} \mathrm{CO}_{2}\right)_{2} \cdot \mathrm{H}_{2} \mathrm{O}$ and $\mathrm{Sr}\left(\mathrm{CH}_{3} \mathrm{CO}_{2}\right)_{2}$ (the amount of water used was only the necessary to dissolve the acetates) were added to a mixture of TEOS, PDMS and the remaining $\mathrm{H}_{2} \mathrm{O}$. Afterwards, isopropanol was added and the medium was acidified with $\mathrm{HCl}$. The prepared solutions were then stirred for 2 hours. After that TiPr, previously chelated with EtAcAc using a 1:2 propoxide/chelating agent molar ratio, was added. The final mixture was then stirred for another 3 hours at room temperature and then poured into $15 \mathrm{~mm}$ diameter polyethylene cylindrical containers. The preparation was kept for a week at room temperature for gelation and then placed in an oven at $60^{\circ} \mathrm{C}$ during another week for aging. After that the gels were dried at $150^{\circ} \mathrm{C}$ for $24 \mathrm{~h}$. Monolithic samples in the shape of cylinders were obtained without visible cracks. Cylinders were cut into disks with a diameter of ca. $15 \mathrm{~mm}$ and thickness of ca. $1.5 \mathrm{~mm}$ using a Struers Secotom-10 cutting machine. The preparation was named C5S5 regarding calcium and strontium Ca/TEOS and Sr/TEOS molar ratios $\times 100$. For a better understanding of the influence of substituting calcium by strontium in the hybrid composition, results obtained with an equivalent composition with 0.10 $\mathrm{Ca} / \mathrm{TEOS}$ molar ratio and no strontium, named here $\mathrm{C} 10$, were used for comparison. 


\subsection{Sample characterization}

The samples structures were analyzed by FT-IR spectroscopy, ${ }^{1} \mathrm{H}$ MAS (magical angle spinning), ${ }^{29} \mathrm{Si}$ MAS and ${ }^{29} \mathrm{Si}-\left\{{ }^{1} \mathrm{H}\right\}$ CP-MAS (cross-polarization magical angle spinning) NMR, and SAXS, using the experimental conditions described in a previous work [16]. The surface topography of sample discs was evaluated using a 3D optical variation system IFM G4 (Alcona). Line and area measurements were done according to the recommendations described by the ISO standards 4287, 4288 and 25178. The following parameters were measured: arithmetic mean deviation of the surface $(\mathrm{Ra})$, root-mean-square deviation of the surface $(\mathrm{Rq})$, maximum height of summits (Rp), maximum depth of valleys $(\mathrm{Rv})$, and total height of the surface (Rt). In addition, the fractal dimension (Df) and the developed area ratio (Sdr, ratio between the interfacial and the projected area) were also calculated.

The potential bioactivity of the materials was evaluated in vitro by immersion of the samples in Kokubos's [17] simulated body fluid (SBF) for 3, 7 and 14 days. The surfaces of the dried samples after soaking in SBF were observed by Scanning Transmission Electron Microscopy (STEM) (Hitachi SU-70) using an accelerating voltage of $25 \mathrm{kV}$, equipped with an Electron Dispersive Spectroscopy (EDS) apparatus (Bruker QUANTAX 400). The same surfaces were also analyzed by Particle Induced X-ray Emission (PIXE) using an Oxford Microbeams OM150 type scanning nuclear microprobe setup and a $2 \mathrm{MeV}$ proton beam generated by a $2.5 \mathrm{MV}$ Van de Graaff accelerator. The proton beam was focused down to $3 \times 4 \mu m^{2}$ and the beam raster scanned over the sample surface covering an area up to $2640 \times 2640 \mu \mathrm{m}^{2}$. PIXE spectra were collected using a $70 \mathrm{~mm}^{2} \mathrm{Si}(\mathrm{Li}) \mathrm{X}$-ray detector. The system allows efficient elemental distribution mapping (using the characteristic $\mathrm{X}$-rays of elements heavier than $\mathrm{Si}$ ) from which particular areas or points can be selected for obtaining spectra for representative quantitative analysis. Operation and basic data manipulation, including elemental distribution mapping, was achieved through the OMDAQ software code, and quantitative analysis with the DAN32 program [18]. Further system details can be found elsewhere [19]. The concentrations of $\mathrm{Ca}, \mathrm{P}, \mathrm{Sr}$ and $\mathrm{Ti}$ in the supernatant liquid were determined by inductively coupled plasma (ICP) (Jobin-Yvon JY70 Plus spectrometer). 
Cut discs were sterilized using a total gamma irradiation dose of $25 \mathrm{kGy}$, the dose usually recommended $[20,21]$ to achieve a Sterility Assurance Level (SAL) of $10^{-6}$ (the probability of a micro-organism to survive after the process) when the natural contamination level and microorganism types cannot be calculated, in a procedure already described [22].

\subsection{Osteoblastic cytocompatibility}

Human osteoblastic-like MG63 cells (ATCC number CRL-1427 ${ }^{\mathrm{TM}}$ ), of passage 25 , were cultured in a-MEM, supplemented with $10 \%$ fetal bovine serum, 50 $\mu \mathrm{g} \cdot \mathrm{ml}^{-1}$ ascorbic acid, $50 \mu \mathrm{g} \cdot \mathrm{ml}^{-1}$ gentamicin and $2.5 \mu \mathrm{g} \cdot \mathrm{ml}^{-1}$ fungizone, at $37^{\circ} \mathrm{C}$, in a humidified atmosphere of $5 \% \mathrm{CO}_{2}$ in air. For sub-culturing, the cell layer (at around $70-80 \%$ confluence) was detached with trypsin - EDTA solution $(0.05 \%$ trypsin, $0.25 \%$ EDTA; 5 minutes, $37^{\circ} \mathrm{C}$ ). The cell suspension was used in the experiments.

Cells were seeded over the materials' samples, at a density of $2 \times 10^{4}$ cells. $\mathrm{cm}^{-2}$, and were cultured for 10 days. Cell behavior was characterized throughout the culture time for cell proliferation, alkaline phosphatase activity and observation by SEM.

DNA content. Cell proliferation was evaluated by analyzing the DNA content, using the PicoGreen DNA quantification assay (Quant-iT ${ }^{\mathrm{TM}}$ PicoGreenR dsDNA Assay Kit, Molecular Probes Inc., Eugene. At each time-point, culture medium was removed and the cultures were treated with Triton X-100 (Sigma, 0.1\%, 5 $\mathrm{min}$ ) to lyse the cell layer. DNA was assessed in the cellular lysates, according to manufacturer's instructions. Fluorescence was measured on an ELISA reader (Synergy HT, Biotek) at wavelengths of 480 and $520 \mathrm{~nm}$, excitation and emission respectively, and corrected for fluorescence of reagent blanks. The amount of DNA was calculated by extrapolating a standard curve obtained by running the assay with the given DNA standard.

ALP activity. ALP activity was evaluated in cell lysates $(0.1 \%$ Triton X-100, 5 $\min$ ) by the hydrolysis of $p$-nitrophenyl phosphate in alkaline buffer solution $\left(\mathrm{pH} 10.3 ; 30 \mathrm{~min}, 37^{\circ} \mathrm{C}\right)$ and colorimetric determination of the product $(p-$ 
nitrophenol) at $400 \mathrm{~nm}$ in an ELISA plate reader (Synergy HT, Biotek). ALP activity was normalized to total protein content (quantified by Bradford's method) and was expressed as nmol/min. ggprotein $^{-1}$.

SEM observation. Seeded material samples were fixed (1.5\% glutaraldehyde in $0.14 \mathrm{M}$ sodium cacodylate buffer, $\mathrm{pH}=7.3,10 \mathrm{~min}$ ), dehydrated in graded alcohols, critical-point dried, sputter-coated with an Au/Pd thin film (SPI Module Sputter Coater equipment), and observed under a high resolution (Schottky) environmental scanning electron microscope (Quanta 400 FEG ESEM).

Statistical analysis: Three independent experiments were performed; in each experiment, three replicas were accomplished for the biochemical assays and two replicas for the qualitative assays. Results are presented as mean \pm standard deviation (SD). One-way analysis of variance (ANOVA) was used in combination with Bonferroni's post-hoc test to data evaluation. Values of $p \leq$ 0.05 were considered significant.

\section{Results and discussion}

\subsection{FT-IR analysis}

Figure 1 shows the FT-IR spectra obtained for both Ca10 and C5S5 samples. Both exhibit the characteristic bands assigned to $\mathrm{SiO}_{2}$ structural units, PDMS backbone, and to PDMS-SiO 2 hybrid bonds $[5,23,24]$.

Slight differences are observed in the configuration of the region between 1000 and $1250 \mathrm{~cm}^{-1}$, assigned to asymmetric stretching of Si-O-Si bonds in both silica and PDMS groups. Those differences indicate that the partial substitution of calcium by strontium resulted in small variations in the geometry and size of the siloxane condensed species $[25,26]$.

Adsorbed water is present in both compositions according to the bands at ca. $3450 \mathrm{~cm}^{-1}$ and $1640 \mathrm{~cm}^{-1}$ assigned respectively to the deformation and bending vibrational modes of $\mathrm{O}-\mathrm{H}$ bonds [25]. A weak signal at ca. $950 \mathrm{~cm}^{-1}$ is assigned to the symmetrical stretching of $\mathrm{Si}-\mathrm{OH}$ bonds [27]. 
The C-O vibrational modes, from calcium and strontium acetates were not detected due to the sol-gel preparation procedure used [5]: the acetic acid (produced by the protonation of the carboxylic group of calcium acetate in the highly acidic medium used in the synthesis) reacts with the excess of IPA present originating an ester (2-propyl ethanoate). This ester has a boiling point [28] lower than the temperatures used here to produce the samples, which explain the absence of signal due to $\mathrm{C}-\mathrm{O}$ bond.

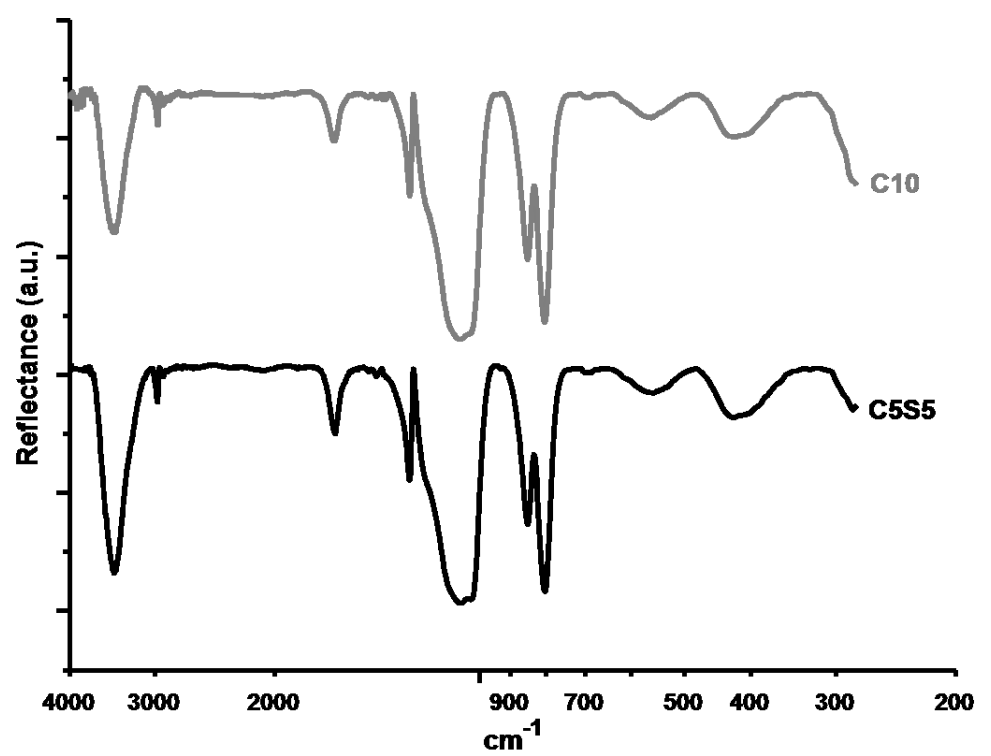

Figure 1: FT-IR spectra of sample C10 and sample C5S5.

\subsection{Solid-State ${ }^{1} \mathrm{H}$ MAS, ${ }^{29}$ Si MAS and ${ }^{29}$ Si- $\left\{{ }^{1} H\right\}$ CP-MAS NMR analysis}

Both samples C5S5 and $\mathrm{C} 10$ were analyzed by ${ }^{1} \mathrm{H}$ MAS, ${ }^{29} \mathrm{Si}$ MAS and by ${ }^{29} \mathrm{Si}-$ $\left\{{ }^{1} \mathrm{H}\right\}$ cross-polarization MAS NMR. The ${ }^{29} \mathrm{Si}$ and ${ }^{29} \mathrm{Si}-\left\{{ }^{1} \mathrm{H}\right\}$ cross-polarization MAS NMR spectra are presented in Figure 2. Distinct groups of Si structural units are observed, one with chemical shifts between -9 to -23 ppm, assigned to difunctional dimethylsiloxane $\mathrm{D}$ structural units $\left(\left(\mathrm{CH}_{3}\right)_{2} \cdot \mathrm{SiO}_{2}\right)$, and another with chemical shifts between -80 to $-110 \mathrm{ppm}$, assigned to tetrafunctional $\mathrm{Q}$ structural units $\left(\mathrm{SiO}_{4}\right)[29]$.

When observing the single pulse spectra, few differences are observed when comparring $\mathrm{C} 10$ with $\mathrm{C} 5 \mathrm{~S} 5$ hybrids, being the most notorious the loss of signal at a chemical shift of ca. $-22 \mathrm{ppm}$ due to $\mathrm{D}$ units located in different positions 
inside PDMS chains containing about 5 dimethylsiloxane units [30]. As explained before [31], these units are in a less constrained environment when compared to $D$ units in positions near to silica $Q$ units or other oxo-metal domains. As a result the signal from those higher mobile structural units is not present in the ${ }^{29} \mathrm{Si}-\left\{{ }^{1} \mathrm{H}\right\}$ CP-MAS spectra due to the lack of efficiency of the cross-polarization (CP) sequence. Based in the authors' previous findings when using the present sol-gel protocol, strontium, like calcium and titanium, are located at the surface of silica domains. Considering that and knowing that titanium alkoxides, like titanium isopropoxide $\mathrm{Ti}(\mathrm{OPri})_{4}$, act as a catalyst of the condensation reactions of siloxane units into longer PDMS chains [49], it is assumed by the authors of the present study that strontium hinders these reactions.

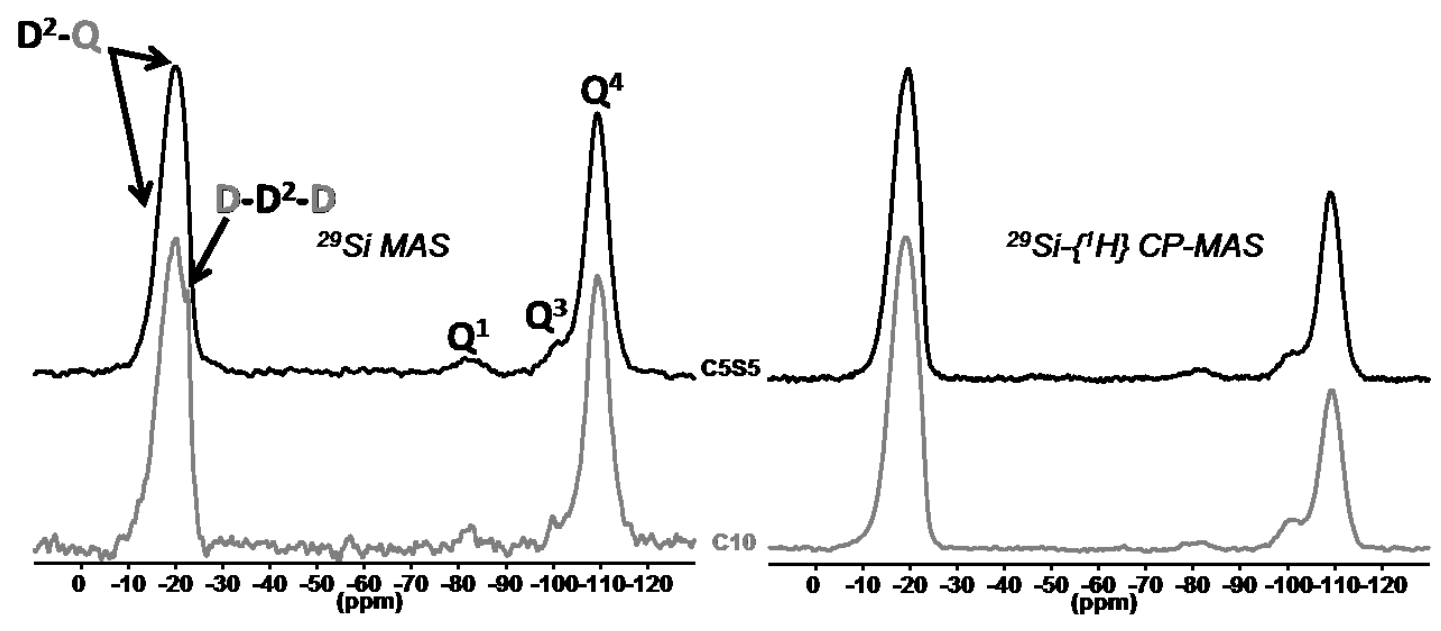

Figure 2: ${ }^{29}$ Si MAS NMR and ${ }^{29}$ Si- $\left\{{ }^{1} H\right\}$ CP-MAS NMR spectra of sample C10 and sample C5S5.

So, partial substitution of calcium by strontium will have little influence in the coordination of silica domains (distribution of $Q$ groups). This was also observed by other authors [32] who studied the influence of the replacement of $\mathrm{Ca}$ by $\mathrm{Sr}$ in the structure of bioactive glasses. According to these authors, the partial substitution of calcium by strontium did not result in different $Q$ group distribution in the ${ }^{29} \mathrm{Si}$ MAS NMR spectra.

C10 and C5S5 samples were analyzed by ${ }^{1} \mathrm{H}$ MAS NMR and the results are depicted in Figure 3. A peak at 0.08 and at 0.13 ppm is assigned to $\mathrm{CH}_{3}$ groups 
in C5S5 and C10 samples respectively. A greater or smaller width of these peaks is associated to changes in the $\mathrm{CH}_{3}$ groups mobility due to the vicinity of $Q$ units, or other metal-oxide units, in a more rigid cross-linked $D-Q$ structure $[30,33]$. As observed in the ${ }^{29} \mathrm{Si}$ and in the ${ }^{29} \mathrm{Si}-\left\{{ }^{1} \mathrm{H}\right\}$ CP-MAS spectra, C10 samples have longer PDMS chains than C5S5 which is in line with the broader peak presented by the C5S5 sample in the ${ }^{1} \mathrm{H}$ spectra. A sharp peak at ca. 4.8 ppm has been assigned to physisorbed water molecules [33,34], probably related to the inclusion of $\mathrm{Ca}$ in the hybrids composition. A closer observation of the peak in the C5S5 spectra reveals that it can be deconvoluted in two peaks: a higher one at $4.9 \mathrm{ppm}$, and a smaller and broader one at $4.7 \mathrm{ppm}$, indicating the existence of physisorbed water in two structurally different sites.

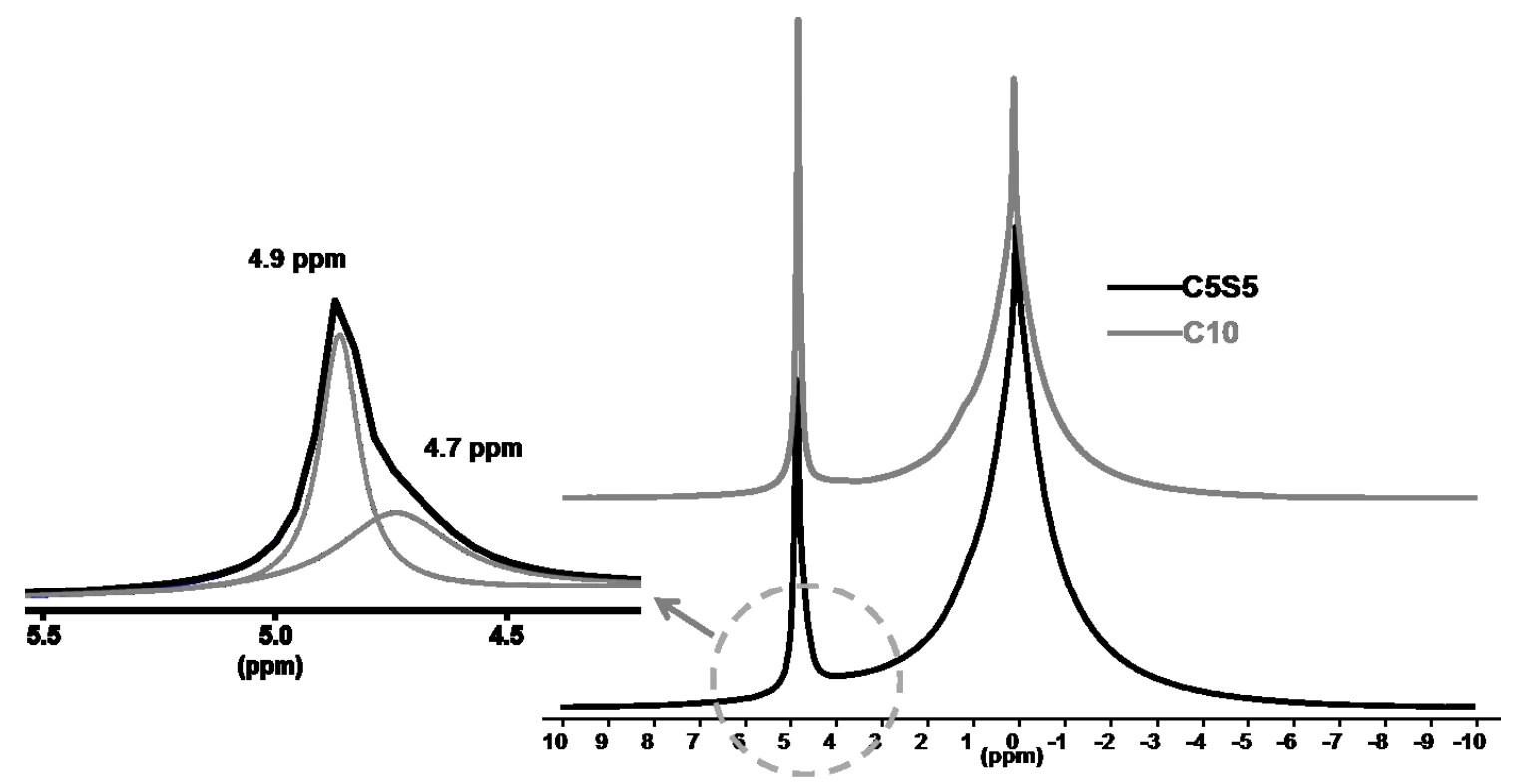

Figure $3:{ }^{1} \mathrm{H}$ MAS NMR spectra for both $\mathrm{C} 10$ and C5S5 samples.

\subsection{Small angle $X$-ray scattering}

Small angle X-ray scattering (SAXS) was performed for both C10 and C5S5 samples and the results are shown in Figure 4 and Table 1. The log-log plot of scattering intensities $I(q)$ versus scattering vector module $q$ can be divided in three different regions. At low values of $q$ (region I in Figure 8.4), the intensity $I(q)$ of scattered photons is described by a simple power-law equation $I(q)=$ $A / q^{d}+$ background, being $A$ the equation pre-factor and $d$ a fractal dimension (for 
mass fractals $d<3$, for surface fractals $3<d<4$, and for diffuse interfaces $d>$ 4) [35]. Table 1 shows that sample C10 presents a fractal dimension value $(d=$ 2.8) indicative of a dense mass fractal, whereas sample C5S5 presents a fractal dimension which corresponds to a dense well defined structure with a smooth surface $(d=3.6)$.

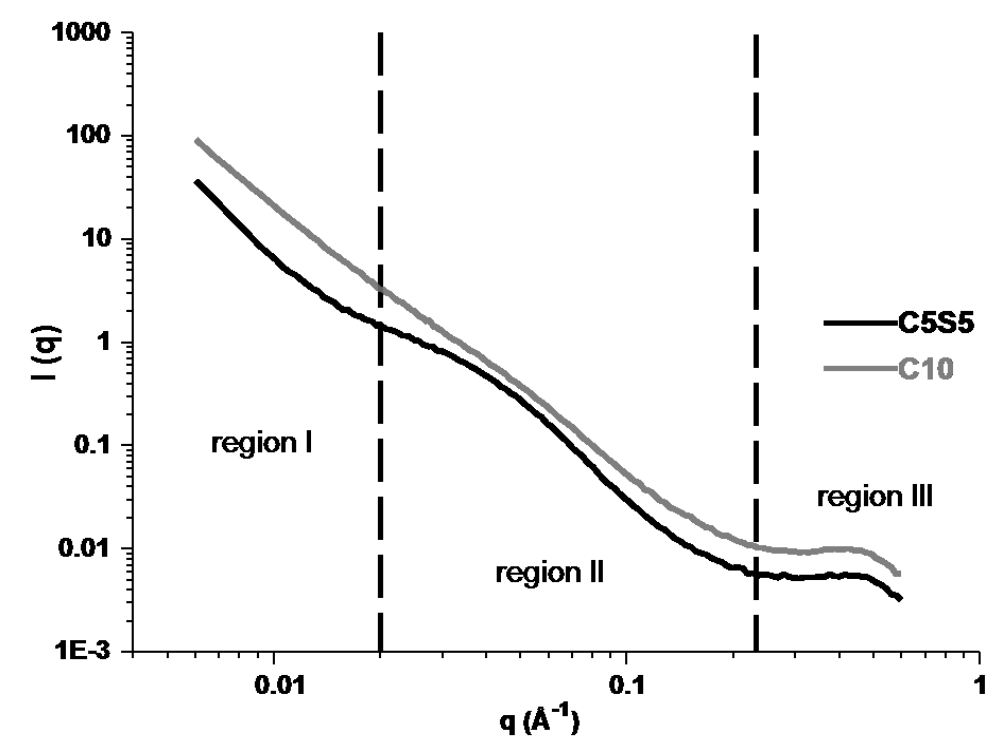

Figure 4: SAXS spectra of sample C10 and sample C5S5.

At intermediate values of $q$ (region II in Figure 4) the scattering plots present a region that can be defined by Guinier regime [36] followed by a power law, and defined by Beaucage unified equation $I(q)=I_{0} \exp \left(-q^{2} R_{g}^{2} / 3\right)+B\left(1 / q^{*}\right)^{\beta}+$ background $[37,38]$ where $I_{0}$ is the Guinier pre-factor, $B$ is the power-law prefactor and $\beta$ its fractal dimension. $R_{g}$ is the radius of gyration, related with the size of the largest heterogeneities, and $q^{*}$ a value defined by $q^{*}=$ $q /\left[\operatorname{erf}\left(k q R_{g} / \sqrt{6}\right)\right]^{3}$ where $\mathrm{k}$ is an empirical constant [38]. Values of $R_{g}$ and $\beta$ were calculated by least square fitting of $I(q)$. Heterogeneities diameter, $D$, was calculated assuming that they have a spherical geometry and using the following equation $D=2(5 / 3)^{1 / 2} R_{g}$. The values in Table 1 show that the heterogeneities diameter, $D$, similar in both C10 and C5S5 samples (around $100 \AA$ diameter), are close to the values published for secondary particles in $\mathrm{PDMS}-\mathrm{SiO}_{2}$ hybrid systems [16,39]. The fractal dimension $\beta$, characteristic of 
the power law regime associated to those heterogeneities, indicate that they can be described by a mass fractal, with $\beta \approx 3$. This is indicative that, in both C10 and C5S5 samples, the heterogeneities growth follows the reaction limited monomer-cluster model [40], being this related with the presence of titanium and the instability of Ti-O-Si bonds in acidic aqueous solutions [16,41,42].

Table 1: values of power exponent $d$, radius of gyration $R_{g}$, the equivalent diameter $D$, and power exponent $\beta$, all determined from the SAXS plots, for both samples.

\begin{tabular}{lcc}
\hline & C10 & C5S5 \\
\cline { 2 - 3 } & & \\
power law exponent $d$ (region $I)$ & 2.8 & 3.6 \\
radius of gyration $R_{g}(\AA)$ & 38 & 43 \\
heterogeneities diameter $D(\AA)$ & 98 & 111 \\
power law exponent $\beta($ region II) & 2.9 & 3.1 \\
\hline
\end{tabular}

The third region at high values of $q$ (region III in Figure 4 ) is defined in both $\mathrm{C} 10$ and C5S5 by a peak, which corresponds to correlations between similar neighboring structures in a lattice. According to the literature [43], the peak height is related to the number of coordinated neighbors at a characteristic distance $a$ defined by $a=2 \pi / q$. As explained in authors previous works [16,23] this characteristic distance is the distance between metal-oxo domains (main silica primary particles) embedded in the siloxane network [44-46]. For both samples this characteristic distance is ca. $13 \AA$ and the peak shape and height are very similar, leading to assume that the partial substitution of calcium by strontium have little effect on the coordination of primary silica domains. In fact, the differences happen when larger structures are formed, supporting the idea that both calcium and strontium are preferably located at the surface of these structures. 


\subsection{Surface topography analysis}

Surface topography of discs of $C 10$ and C5S5 samples was evaluated using a 3D optical variation system (Figure 5). Five parameters that are relevant for cell adhesion and proliferation events were measured: arithmetic mean deviation of the surface $\left(R_{a}\right)$, root-mean-square deviation of the surface $\left(R_{q}\right)$, maximum height of summits $\left(R_{p}\right)$, maximum depth of valleys $\left(R_{v}\right)$, and total height of the surface $\left(R_{t}\right)$. The surface fractal dimension $\left(D_{f}\right)$ and the developed area ratio $\left(S_{d r}\right)$ were also calculated and the results are presented in Table 2.

Table 2: Surface topography related values of samples' discs (standard deviation values in brackets).

\begin{tabular}{ccc}
\hline & C10 & C5S5 \\
\cline { 2 - 3 } $\mathrm{R}_{\mathrm{a}}(\mu \mathrm{m})$ & $35.58(0.08)$ & $6.54(0.00)$ \\
$\mathrm{R}_{\mathrm{q}}(\mu \mathrm{m})$ & $49.98(0.12)$ & $8.84(0.00)$ \\
$\mathrm{R}_{\mathrm{p}}(\mu \mathrm{m})$ & $116.68(0.02)$ & $20.07(0.08)$ \\
$\mathrm{R}_{\mathrm{v}}(\mu \mathrm{m})$ & $476.36(0.10)$ & $46.51(0.02)$ \\
$\mathrm{R}_{\mathrm{t}}(\mu \mathrm{m})$ & $593.04(0.02)$ & $66.58(0.10)$ \\
$\mathrm{D}_{\mathrm{f}}$ & 2.3 & 2.1 \\
$\mathrm{~S}_{\mathrm{dr}}(\%)$ & 2782.4 & 159.9 \\
\hline
\end{tabular}



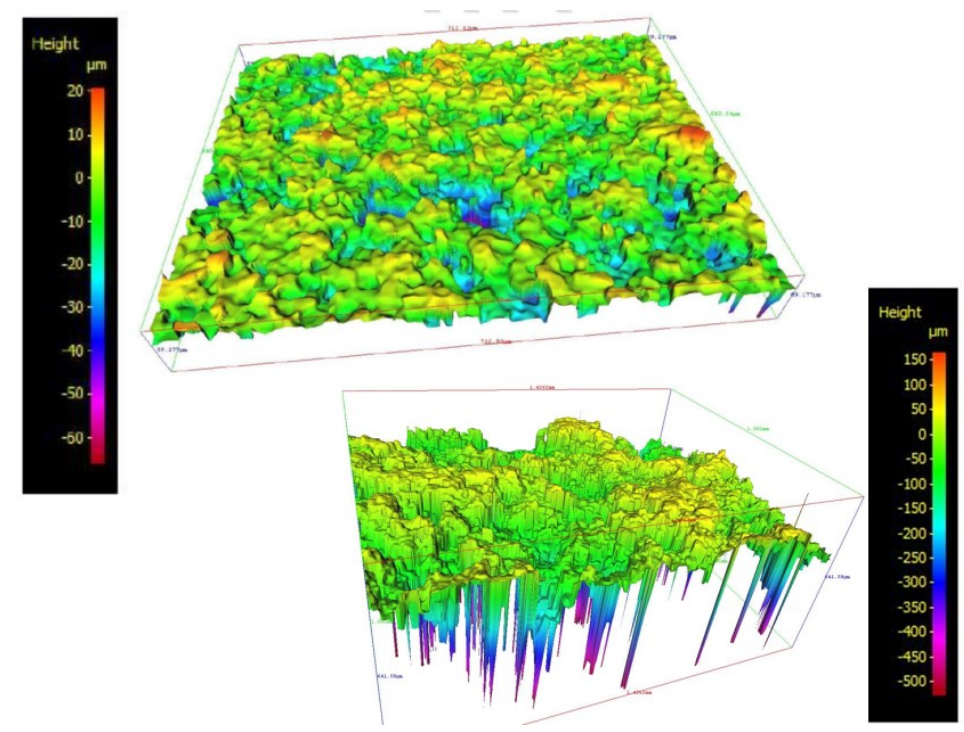

Figure 5: 3D topography of sample C5S5 (top) and sample C10 (bottom).

The results (Table 2 and Figure 5 ) show that the partial substitution of calcium by strontium produces a smother surface. While respecting the difference in length scales, this observation is in accordance to what was observed in the SAXS analysis.

\subsection{In vitro evaluation}

\subsubsection{Bioactivity studies}

The surfaces of discs from C10 and C5S5 samples were observed by SEM and analysed by EDS after they have been immersed in Kokubos's [17] simulated body fluid (SBF) for 3, 7 and 14 days. SEM images obtained before and after immersion (14 days) are shown in Figure 6 as well as the EDS spectra of the samples after immersion. 


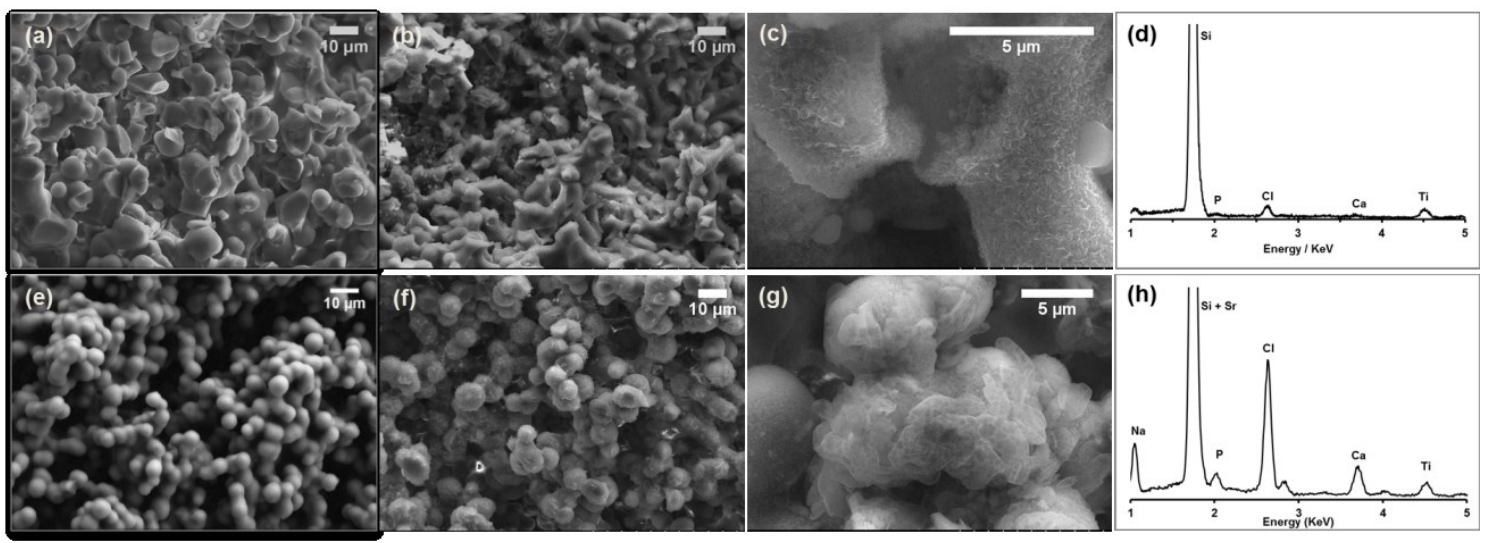

Figure 6: SEM images of C10 (a) and C5S5 (e) surfaces before, and after immersion in SBF for 14 days: (b) and (c) for C10, and (f) and (g) for C5S5 samples. EDS spectra of (d) C10 and (h) C5S5 sample after immersion in SBF for 14 days.

The presence of surface precipitates after soaking the C10 and C5S5 samples in SBF for 14 days is confirmed with the EDS spectra, which show that they contain phosphorous. The EDS spectra also show the presence of $\mathrm{Cl}$ due to the $\mathrm{HCl}$ used in the samples preparation and $\mathrm{Na}$ (from the SBF). The precipitates were analysed by X-ray diffraction (Figure 7) showing that, for both compositions, an apatite-like calcium phosphate was identified [47].

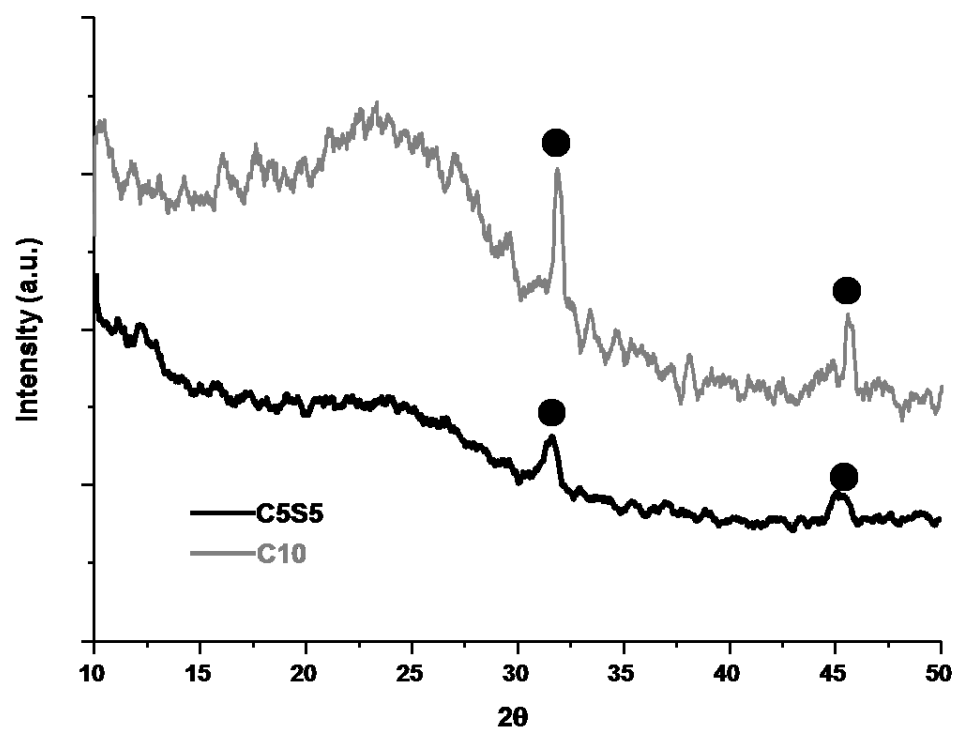

Figure 7: XRD spectra of C5S5 and C10 samples after immersion in SBF for 14 days. Symbol • indicate apatite related peaks [47]. 
ICP results in Figure 8 show the $\mathrm{Ca}, \mathrm{P}$ and $\mathrm{Sr}$ ions concentration in the supernatant liquids in relation to their initial concentrations in SBF. It can be observed that, after 3 days, strontium ions are released from the C5S5 sample, a trend verified until 7 days of immersion. For longer immersion times (14 days) a decrease in the strontium concentration is observed.

The amount of strontium released is well above the minimum value $\left(9 \mathrm{mg} \cdot \mathrm{L}^{-1}\right)$ that, according to the literature [48], can induce osteoblasts activity and inhibit the osteoclasts bone resorption and, at the same time, is much lower than the one reported as cytotoxic (above $2100 \mathrm{mg} \cdot \mathrm{L}^{-1}$ ).

The ICP results also showed that, for both compositions, no titanium was detected in the supernatant liquid, even for longer soaking times in SBF.
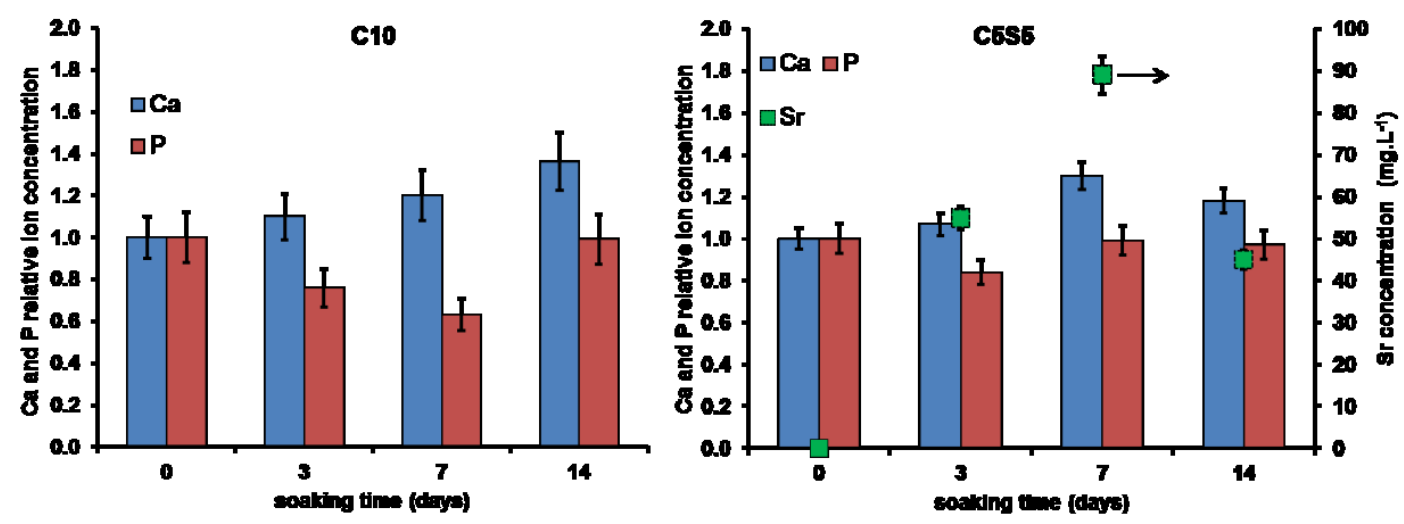

Figure 8: Ca and $P$ relative ion concentration for $C 10$ and C5S5 samples, and Sr absolute concentration for C5S5 sample, immersed in SBF for 0, 3, 7 and 14 days.

For both compositions, slight differences are observed in the concentration of calcium in the supernatant liquid, although one can observe a trend for $\mathrm{Ca}$ release in the $\mathrm{C} 10$ composition. In the case of phosphorous, a reduction of its concentration on the supernatant liquid until 7 days of soaking is verified for C10 sample. An increase in the phosphorous concentration for longer soaking times (14 days) suggests that the surface phosphorous-containing precipitates 
dissolve in the SBF. Regarding C5S5 samples no significant variations of the $P$ concentration seem to occur throughout the assayed immersion period.

Particle Induced X-ray Emission (PIXE) offers better peak to noise ratios and consequently much higher trace element sensitivities when compared to electron based x-ray analytical techniques such as EDS. To have more accurate information about the surface elemental changes, C5S5 sample surfaces were analyzed before and after soaking in SBF for 7 and 14 days using PIXE. Elemental maps for a $2640 \times 2640 \mu \mathrm{m}^{2}$ area were obtained and are shown in Figure 9 for C5S5 surfaces before and after soaking in SBF for 14 days. It is clear, from the elemental maps, that the analyzed elements are homogeneously distributed in the initial C5S5 surface. After 14 days of soaking in SBF calcium the elemental maps of $\mathrm{Ca}$ and $\mathrm{P}$ indicate that phosphate precipitates cover some zones (an example is signalized with a red circle in the Ca map) confirming the results obtained by EDS and DRX. It can also be noted that these areas have a higher concentration of $\mathrm{Sr}$ and $\mathrm{Cl}$, which reveals that both elements also precipitate in the sample surface after having been previously dissolved in the SBF. It is possible that, once in aqueous solution, some strontium ions react with chlorine to give strontium chloride, despite no peaks of this compound have been found in the XRD spectra.

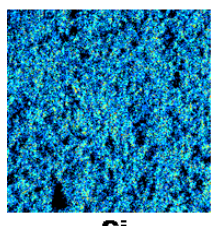

Si

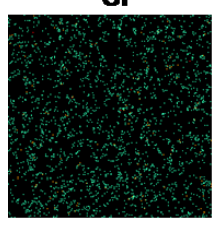

Sr

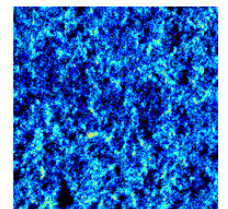

CI

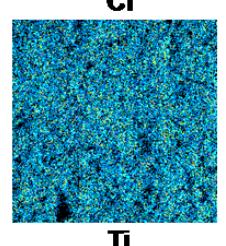

O days

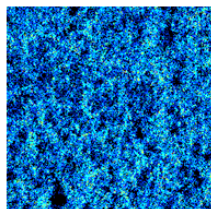

Ca

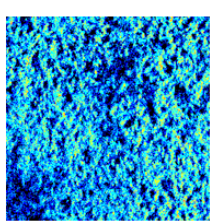

Si

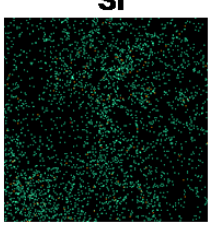

Sr
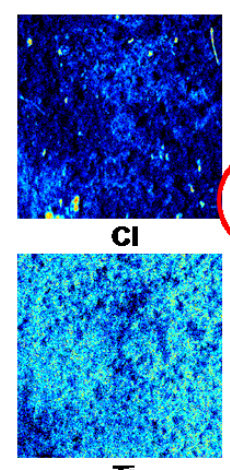

TI

14 days

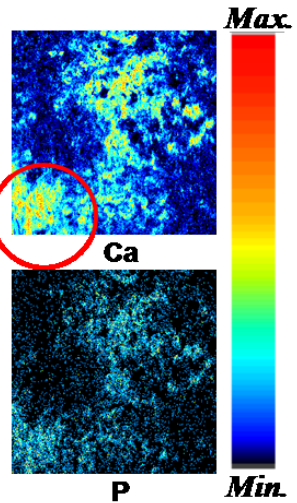

Min.

Figure 9: $2640 \times 2640 \mu m^{2}$ PIXE elemental maps of C5S5 sample surfaces before and after immersion in SBF for 14 days (colour bar for signal intensity red circle indicate an example of a Ca high concentration zone). 
Figure 10 shows the changes in the proportions of different elements in the C5S5 sample surface before and after immersion in SBF for 7 and 14 days. Using the results obtained from the quantitative analysis, molar ratios were calculated in relation to the concentration of titanium since, as referred above, there is no evidence of titanium dissolution in SBF (thus the influence of the surface morphology is reduced). By comparing the concentrations of calcium and strontium in the C5S5 sample before immersion, it appears that strontium is in higher concentration on the surface. The variations of strontium concentration throughout the assayed immersion period are in good agreement with the results obtained from ICP analysis, indicating that, after having been released (until 7 days of soaking), strontium is reincorporated in the surface structure.

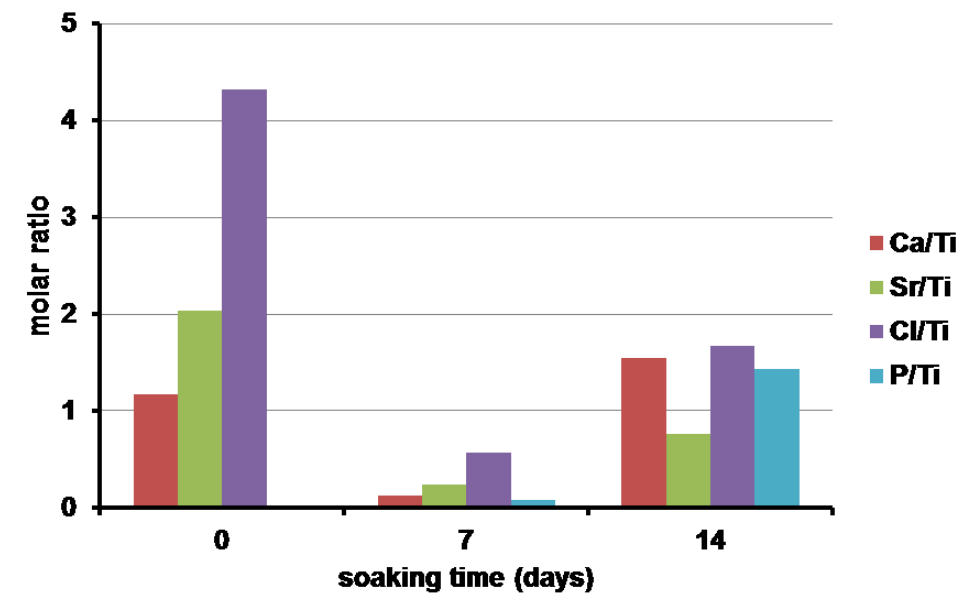

Figure 10: Ca/Ti, Sr/Ti, CI/Ti and P/Ti molar ratios determined by PIXE for C5S5 samples immersed in SBF at 0, 7 and 14 days.

\subsubsection{Biocompatibility studies}

Material samples were seeded with MG63 osteoblastic cells, cultured for 10 days, and evaluated for cell proliferation, ALP activity and observation by SEM.

Cell proliferation, measured by the DNA content (Figure 11), increased gradually throughout the culture period in both materials until day 8 , attaining a stationary phase afterwards. On day 1, values were slightly increased on samples C5S5, although without reaching statistical significance. However, cell 
growth rate was significantly higher on samples C5S5 during the first days of incubation, as evident by the increased DNA values at day 5 ( $30 \%)$, compared to that on samples $\mathrm{C} 10$. At days 8 and 10, DNA was similar in both samples, most probably due to the formation of a confluent layer on the two materials. ALP activity also increased during the incubation time. On samples $\mathrm{C} 10$, the activity of this enzyme showed a gradual increase until day 8 , and stabilized afterwards. Instead, on samples C5S5, ALP activity attained maximum values earlier, at day 5 , being approximately constant after that. It is worth to note that, at day 5 , the activity of this enzyme was $\sim 40 \%$ higher on samples C5S5, compared to samples C10. However, peak values for ALP activity were similar in both materials. Results are shown on Figure 11.
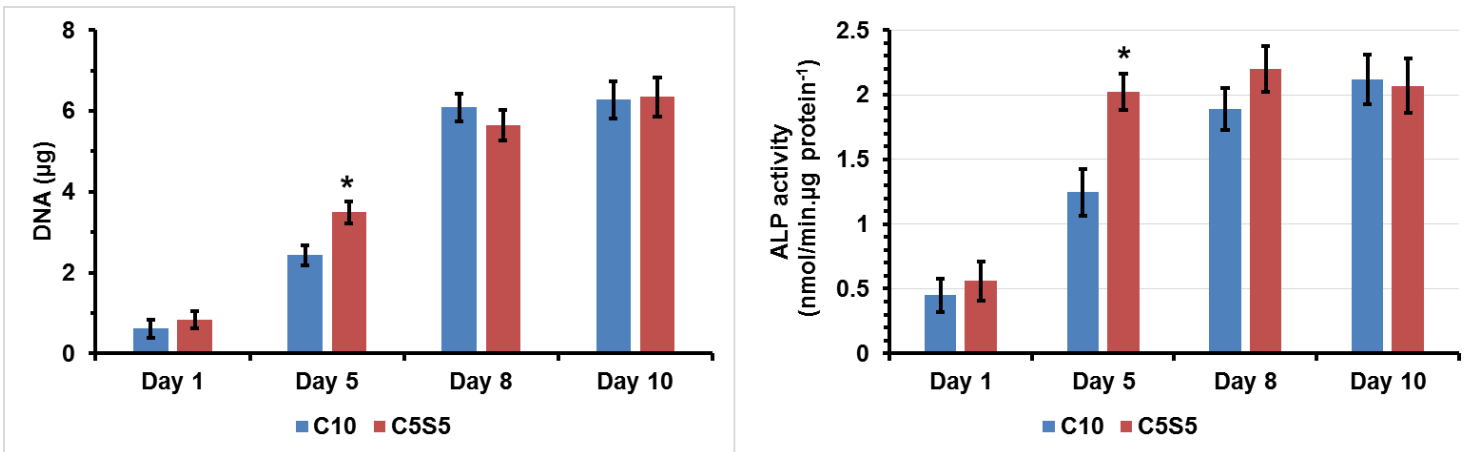

Figure 11: Cell proliferation (left) and alkaline phosphatase activity (right) for both C10 and C5S5 samples. ${ }^{*}$ indicates significant difference compared to C10 $(p<0.05)$.

SEM images of the colonized materials, Figure 12, showed that C10 and C5S5 behaved similarly regarding cell morphology and pattern of cell growth. At day 1 , cells were still round in both materials, but they went through a cytoplasm expansion process, acquiring an elongated appearance, as seen on day 5 images; additionally, they appeared healthy, establishing cell-to-cell contacts and exhibiting a close interaction with the material surface, spreading over the rough topography and growing towards/inside the surface irregularities. At day 8, a confluent and well-organized cell layer was observed on both samples, as anticipated by the similar DNA content measured at this culture time. 

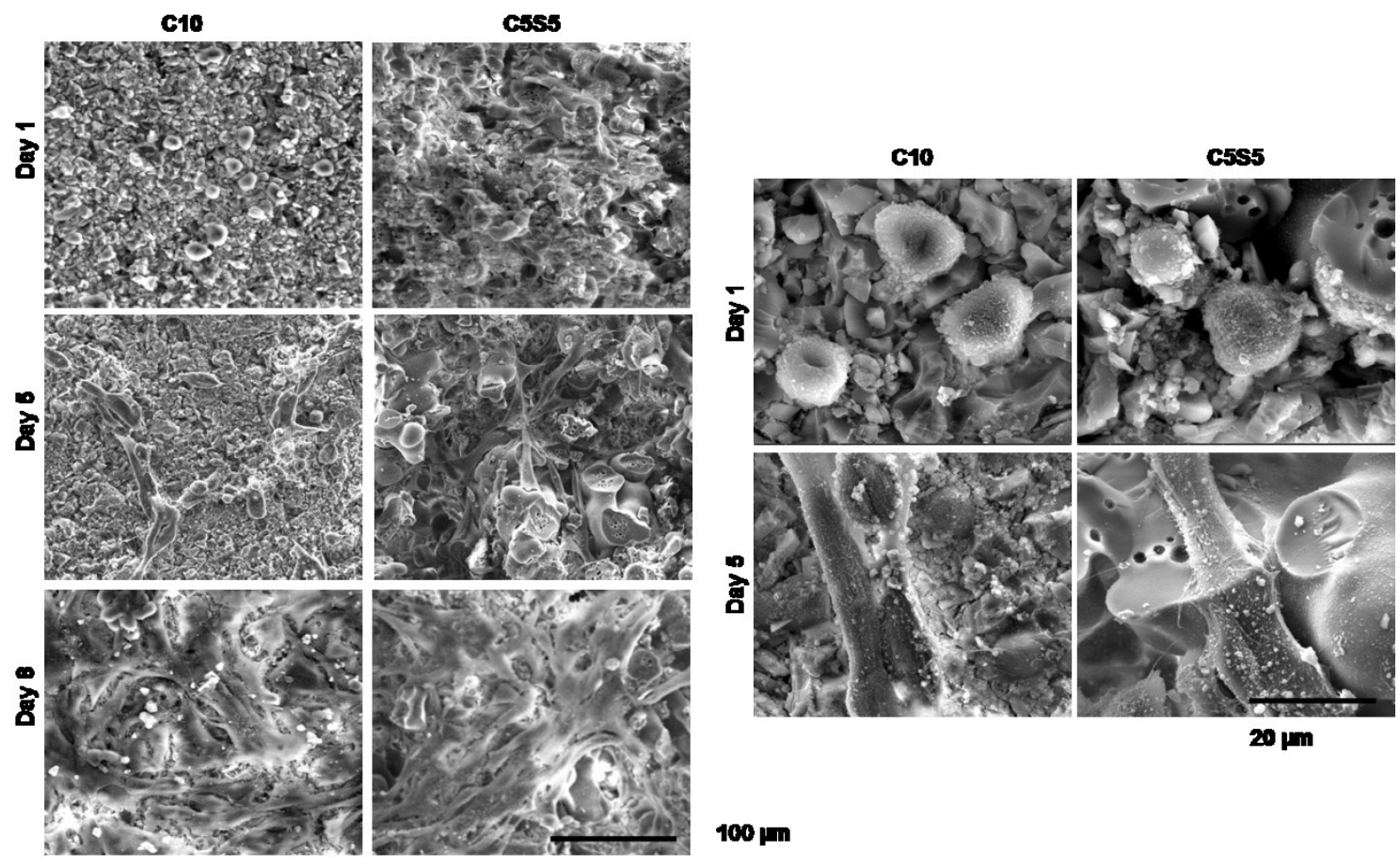

Figure 12: Surfaces of C10 and C5S5 samples seeded with MG63 osteoblastic cells. SEM observations obtained after 1, 5 and 8 days. Photos displayed at two different magnifications: at left bar $=100 \mu \mathrm{m}$, at right bar $=20 \mu \mathrm{m}$.

As described above, C5S5 samples presented an improved osteoblastic cell response compared to $\mathrm{C} 10$ samples, namely an initial higher cell growth rate associated with an earlier peaking of ALP activity. ALP is a membrane-bound enzyme that begins to be synthesized earlier on the osteoblastic differentiation pathway, showing a significant increase later, in more mature cells, playing a significant role in the onset of matrix mineralization [49]. Thus, cell response to C5S5 suggested a shortened cycle for the osteoblastic maturation, which would speed up bone formation events, according to the established osteogenic proliferation/differentiation pathway [49]. The release of $\mathrm{Sr}$ ions from the material into the culture medium might have a contribution for this inductive effect. As described above, after the immersion of the samples in SBF, the concentration of $\mathrm{Sr}$ ions in the supernatant increased significantly during the first week of incubation, attaining levels within those reported to be inductive in osteoblastic cells [50]. Cell proliferation rate and ALP activity on C5S5 samples 
were also significantly stimulated during this culture period. The improved behavior of this material is in agreement with a variety of studies showing the enhancing effects of $\mathrm{Sr}$ on osteogenesis in vitro using different cell sources [13]. The inductive effects are evident both when $\mathrm{Sr}$ is added to the cell culture medium [50-52], or when it is incorporated into calcium phosphate biomaterials, like hydroxyapatite [53-55] and bioglasses [7-9,56,57]. Several molecular mechanisms have been proposed to the stimulatory effects of $\mathrm{Sr}$ on osteoblastic cells [13]. The calcium sensing receptor seems to have a major role, due to the ability to sense other divalent ions apart from $\mathrm{Ca}^{2+}$. Binding of $\mathrm{Sr}$ ions to this receptor leads to the activation of several relevant intracellular mechanisms, as the release of intracellular $\mathrm{Ca}^{2+}$ and the upregulation of RasMAPK $[52,58]$ and the Wnt-Catenin [59] signaling pathways, which modulate the expression of genes promoting osteoblastic proliferation, differentiation and survival [13].

In addition to the eventual Sr-mediated stimulation of the osteoblastic response, other factors, related with the physic-chemical profile of the develop materials can also influence the cell response. In fact, anchorage-dependent cells are inherently sensitive to the surface microroughness, although this parameter is a controversial factor affecting cell behavior [60]. Microroughness is reported to be associated with positive effects on cell adhesion, growth and differentiation, within certain range values, and dependent on other concomitant surface parameters. Topography seems to play a major role [60,61]. As described above, the partial substitution of $\mathrm{Ca}$ by $\mathrm{Sr}$ in $\mathrm{C} 5 \mathrm{~S} 5$ samples resulted in a significant decrease of the tested roughness parameters. C10 samples showed a rough surface with a great difference between the height of summits and the depth of valleys. Although the high surface area, the highly irregular topography may hinder cell adhesion and proliferation. Instead, samples C5S5, with a lower surface roughness, exhibited a relatively homogeneous topography, which might favor cell/surface interactions [60,61].

\section{Conclusions}

A monolithic hybrid material in the system $\mathrm{PDMS}-\mathrm{SiO}_{2}-\mathrm{TiO}_{2}-\mathrm{CaO}-\mathrm{SrO}$ was prepared using a sol-gel procedure developed by the present authors. When 
partially replacing calcium, strontium hinders the self-condensation of PDMS chains resulting in the formation of denser structures at an earlier stage of the sol-gel process. This leads to a more compact microstructure with smother surface. Like calcium, strontium ions are preferably located in the surface of silica nanoparticles. The potential bioactivity of the material was evaluated by immersion tests in a synthetic physiological fluid, which showed that both calcium and strontium are released. The amount of strontium released is well above the minimum value $\left(9 \mathrm{mg} \cdot \mathrm{L}^{-1}\right)$ that, according to the literature, can induce osteoblasts activity and inhibit the osteoclasts bone resorption and, at the same time, much lower than the one reported as cytotoxic (above $2100 \mathrm{mg} \cdot \mathrm{L}^{-1}$ ). This was confirmed by cytocompatibility tests, which demonstrated that the composition containing both calcium and strontium present an improved osteoblastic cell response, namely a higher cell growth rate associated with an earlier peaking of ALP activity.

\section{Acknowledgments}

This work was financed by the JECS Trust (Contract 201467), FEDER funds (Program COMPETE) and by FCT funds, by the grant SFRH/BD/72074/2010 and also developed in the scope of the project CICECO-Aveiro Institute of Materials (Ref. FCT UID/CTM /50011/2013), financed by national funds through the FCT/MEC and when applicable co-financed by FEDER under the PT2020 Partnership Agreement.

\section{References}

[1] C. Sanchez, L. Rozes, F. Ribot, C. Laberty-Robert, D. Grosso, C. Sassoye, et al., "Chimie douce": A land of opportunities for the designed construction of functional inorganic and hybrid organic-inorganic nanomaterials, Comptes Rendus Chim. 13 (2010) 3-39.

[2] T. Kokubo, H.M. Kim, M. Kawashita, Novel bioactive materials with different mechanical properties, Biomaterials. 24 (2003) 2161-2175.

[3] A.J. Salinas, J.M. Merino, F. Babonneau, F.J. Gil, M. Vallet-Regi, Microstructure and macroscopic properties of bioactive $\mathrm{CaO}-\mathrm{SiO}_{2}-\mathrm{PDMS}$ hybrids, J. Biomed. Mater. Res. Part B-Applied Biomater. 81B (2007) 274-282. 
[4] J.R. Jones, Review of bioactive glass: From Hench to hybrids, Acta Biomater. 9 (2013) 4457-4486.

[5] A.G.B. Castro, J.C. Almeida, I.M.M. Salvado, F.M.A. Margaca, M.H. V Fernandes, A novel hybrid material with calcium and strontium release capability, Mater. Lett. 88 (2012) 12-15.

[6] A. Hoppe, N.S. Güldal, A.R. Boccaccini, A review of the biological response to ionic dissolution products from bioactive glasses and glassceramics., Biomaterials. 32 (2011) 2757-74.

[7] E. Gentleman, Y.C. Fredholm, G. Jell, N. Lotfibakhshaiesh, M.D. O'Donnell, R.G. Hill, et al., The effects of strontium-substituted bioactive glasses on osteoblasts and osteoclasts in vitro, Biomaterials. 31 (2010) 3949-3956.

[8] J. Isaac, J. Nohra, J. Lao, E. Jallot, J.M. Nedelec, A. Berdal, et al., Effects of Strontium-Doped Bioactive Glass on the Differentiation of Cultured Osteogenic Cells, Eur. Cell. Mater. 21 (2011) 130-143.

[9] M.E. Santocildes-Romero, A. Crawford, P. V Hatton, R.L. Goodchild, I.M. Reaney, C.A. Miller, The osteogenic response of mesenchymal stromal cells to strontium-substituted bioactive glasses., J. Tissue Eng. Regen. Med. 9 (2015) 619-31.

[10] M.D. O'Donnell, R.G. Hill, Influence of strontium and the importance of glass chemistry and structure when designing bioactive glasses for bone regeneration, Acta Biomater. 6 (2010) 2382-2385.

[11] W. Zhang, Y. Shen, H. Pan, K. Lin, X. Liu, B.W. Darvell, et al., Effects of strontium in modified biomaterials., Acta Biomater. 7 (2011) 800-8.

[12] P.J. Marie, Strontium ranelate: New insights into its dual mode of action, Bone. 40 (2007) S5-S8.

[13] Z. Saidak, P.J. Marie, Strontium signaling: molecular mechanisms and therapeutic implications in osteoporosis., Pharmacol. Ther. 136 (2012) 216-26.

[14] Y. Zhang, L. Wei, J. Chang, R.J. Miron, B. Shi, S. Yi, et al., Strontiumincorporated mesoporous bioactive glass scaffolds stimulating in vitro proliferation and differentiation of bone marrow stromal cells and in vivo regeneration of osteoporotic bone defects, J. Mater. Chem. B. 1 (2013) 5711.

[15] P. Li, C. Ohtsuki, T. Kokubo, K. Nakanishi, N. Soga, K. de Groot, The role of hydrated silica, titania, and alumina in inducing apatite on implants., J. Biomed. Mater. Res. 28 (1994) 7-15. 
[16] J.C. Almeida, A. Wacha, A. Bóta, L. Almásy, M.H. Vaz Fernandes, F.M.A. Margaça, et al., PDMS-SiO 2 hybrid materials - a new insight into the role of $\mathrm{Ti}$ and $\mathrm{Zr}$ as additives, Polymer 72 (2015) 40-51.

[17] T. Kokubo, H. Takadama, How useful is SBF in predicting in vivo bone bioactivity?, Biomaterials. 27 (2006) 2907-2915.

[18] G.W. Grime, M. Dawson, Recent developments in data acquisition and processing on the Oxford scanning proton microprobe, Nucl. Instruments Methods Phys. Res. Sect. B Beam Interact. with Mater. Atoms. 104 (1995) 107-113.

[19] L.. Alves, M.B.. Breese, E. Alves, A. Paúl, M.. da Silva, M.. da Silva, et al., Micron-scale analysis of SiC/SiCf composites using the new Lisbon nuclear microprobe, Nucl. Instruments Methods Phys. Res. Sect. B Beam Interact. with Mater. Atoms. 161-163 (2000) 334-338.

[20] H. Nguyen, D.A.F. Morgan, M.R. Forwood, Sterilization of allograft bone: is $25 \mathrm{kGy}$ the gold standard for gamma irradiation?, Cell Tissue Bank. 8 (2007) 81-91.

[21] IAEA, Trends in Radiation Sterilization of Health Care Products, Vienna, 2008.

[22] J.C. Almeida, J. Lancastre, M.H. Vaz Fernandes, F.M.A. Margaça, L. Ferreira, I.M. Miranda Salvado, Evaluating structural and microstructural changes of $\mathrm{PDMS}-\mathrm{SiO}_{2}$ hybrid materials after sterilization by gamma irradiation., Mater. Sci. Eng. C. Mater. Biol. Appl. 48 (2015) 354-8.

[23] J.C. Almeida, A.G.B. Castro, J.J.H. Lancastre, I.M. Miranda Salvado, F.M.A. Margaça, M.H.V. Fernandes, et al., Structural characterization of PDMS-TEOS-CaO- $\mathrm{TiO}_{2}$ hybrid materials obtained by sol-gel, Mater. Chem. Phys. 143 (2014) 557-563.

[24] J. Carlos Almeida, A.G.B. Castro, I.M. Miranda Salvado, F.M.A. Margaça, M.H. Vaz Fernandes, A new approach to the preparation of PDMS-SiO 2 based hybrids - A structural study, Mater. Lett. 128 (2014) 105-109.

[25] F. Rubio, J. Rubio, J.L. Oteo, A FT-IR study of the hydrolysis of tetraethylorthosilicate (TEOS)., Spectrosc. Lett. 31 (1998) 199-219.

[26] B. Julian, C. Gervais, E. Cordoncillo, P. Escribano, F. Babonneau, C. Sanchez, Synthesis and characterization of transparent PDMS-metal-oxo based organic anorganic nanocomposites, Chem. Mater. 15 (2003) 30263034.

[27] H. Aguiar, J. Serra, P. Gonzalez, B. Leon, Structural study of sol-gel silicate glasses by IR and Raman spectroscopies, J. Non. Cryst. Solids. 355 (2009) 475-480. 
[28] J. Ortega, C. Gonzalez, J. Peña, S. Galván, Thermodynamic study on binary mixtures of propyl ethanoate and an alkan-1-ol (C2-C4). Isobaric vapor-liquid equilibria and excess properties, Fluid Phase Equilib. 170 (2000) 87-111.

[29] R.H. Glaser, G.L. Wilkes, C.E. Bronnimann, Solid-State Si-29 Nmr of Teos-Based Multifunctional Sol-Gel Materials, J. Non. Cryst. Solids. 113 (1989) 73-87.

[30] F. Babonneau, Hybrid siloxane-oxide materials via sol-gel processing: Structural characterization, Polyhedron. 13 (1994) 1123-1130.

[31] F. Babonneau, N. Baccile, G. Laurent, J. Maquet, T. Azais, C. Gervais, et al., Solid-state nuclear magnetic resonance: A valuable tool to explore organic-inorganic interfaces in silica-based hybrid materials, Comptes Rendus Chim. 13 (2010) 58-68.

[32] Y.C. Fredholm, N. Karpukhina, R. V. Law, R.G. Hill, Strontium containing bioactive glasses: Glass structure and physical properties, J. Non. Cryst. Solids. 356 (2010) 2546-2551.

[33] J. Brus, Solid-state NMR study of phase separation and order of water molecules and silanol groups in polysiloxane networks, J. Sol-Gel Sci. Technol. 25 (2002) 17-28.

[34] E. Leonova, I. Izquierdo-Barba, D. Arcos, A. López-Noriega, N. Hedin, M. Vallet-Regí, et al., Multinuclear Solid-State NMR Studies of Ordered Mesoporous Bioactive Glasses, J. Phys. Chem. C. 112 (2008) 55525562.

[35] P. Schmidt, Some Fundamental Concepts and Techniques Useful in Small-Angle Scattering Studies of Disordered Solids, in: H. Brumberger (Ed.), Mod. Asp. Small-Angle Scatt., Dordrecht, 1995: pp. 1-56.

[36] O. Glatter, O. Kratky, Small angle x-ray scattering, Academic Press, London ; New York, 1982.

[37] G. Beaucage, Approximations Leading to a Unified Exponential/PowerLaw Approach to Small-Angle Scattering, J. Appl. Crystallogr. 28 (1995) 717-728.

[38] G. Beaucage, Small-Angle Scattering from Polymeric Mass Fractals of Arbitrary Mass-Fractal Dimension, J. Appl. Crystallogr. 29 (1996) 134146.

[39] X.-X. Zhang, B.-B. Xia, H.-P. Ye, Y.-L. Zhang, B. Xiao, L.-H. Yan, et al., One-step sol-gel preparation of PDMS-silica ORMOSILs as environment-resistant and crack-free thick antireflective coatings, J. Mater. Chem. 22 (2012) 13132. 
[40] D.W. Schaefer, Polymers, Fractals, and Ceramic Materials, Science (80-. ). 243 (1989) 1023-1027.

[41] L. Crouzet, D. Leclercq, P.H. Mutin, A. Vioux, Organosilsesquioxanetitanium oxide hybrids by nonhydrolytic sol-gel processes. Study of the rearrangement of Si-O-Ti bonds, Chem. Mater. 15 (2003) 1530-1534.

[42] C. Sanchez, F. Ribot, Design of Hybrid Organic-Inorganic Materials Synthesized Via Sol-Gel Chemistry, New J. Chem. 18 (1994) 1007-1047.

[43] M. Kallala, R. Jullien, B. Cabane, Crossover from gelation to precipitation, J. Phys. II. 2 (1992) 7-25.

[44] T.A. Ulibarri, G. Beaucage, D.W. Schaefer, B.J. Olivier, R.A. Assink, Molecular Weight Dependence of Domain Structure in Silica-Siloxane Molecular Composites, MRS Proc. 274 (2011) 85.

[45] R.H. Glaser, G.L. Wilkes, Structure Property Behavior of Polydimethylsiloxane and Poly(Tetramethylene Oxide) Modified Teos Based Sol-Gel Materials .5. Effect of Titaniumisopropoxide Incorporation, Polym. Bull. 19 (1988) 51-57.

[46] C. Guermeur, J. Lambard, J.F. Gerard, C. Sanchez, Hybrid polydimethylsiloxane-zirconium oxo nanocomposites. Part 1 Characterization of the matrix and the siloxane-zirconium oxo interface, J. Mater. Chem. 9 (1999) 769-778.

[47] Christophe Drouet, Apatite formation: why it may not work as planned, and how to conclusively identify apatite compounds., Biomed Res. Int. 2013 (2013) 12 pages.

[48] M. Erol, A. Özyuğuran, Ö. Özarpat, S. Küçükbayrak, 3D Composite scaffolds using strontium containing bioactive glasses, J. Eur. Ceram. Soc. (n.d.).

[49] J.E. Aubin, Mesenchymal stem cell and osteoblast differentiation, in: J.P. Bilezikian, L.G. Raisz, T.J. Martin (Eds.), Princ. Bone Biol., 3rd ed., Academic Press/Elsevier, San Diego, Calif., 2008: p. 2 v. (xxiv, 1942, liv p. + [22] p. of plates).

[50] E. Bonnelye, A. Chabadel, F. Saltel, P. Jurdic, Dual effect of strontium ranelate: Stimulation of osteoblast differentiation and inhibition of osteoclast formation and resorption in vitro, Bone. 42 (2008) 129-138.

[51] G.J. Atkins, K.J. Welldon, P. Halbout, D.M. Findlay, Strontium ranelate treatment of human primary osteoblasts promotes an osteocyte-like phenotype while eliciting an osteoprotegerin response., Osteoporos. Int. 20 (2009) 653-64. 
[52] S. Peng, G. Zhou, K.D.K. Luk, K.M.C. Cheung, Z. Li, W.M. Lam, et al., Strontium promotes osteogenic differentiation of mesenchymal stem cells through the Ras/MAPK signaling pathway., Cell. Physiol. Biochem. 23 (2009) 165-74.

[53] W. Xue, J.L. Moore, H.L. Hosick, S. Bose, A. Bandyopadhyay, W.W. Lu, et al., Osteoprecursor cell response to strontium-containing hydroxyapatite ceramics., J. Biomed. Mater. Res. A. 79 (2006) 804-14.

[54] C. Capuccini, P. Torricelli, E. Boanini, M. Gazzano, R. Giardino, A. Bigi, Interaction of Sr-doped hydroxyapatite nanocrystals with osteoclast and osteoblast-like cells., J. Biomed. Mater. Res. A. 89 (2009) 594-600.

[55] M.L. Zhang, W.Y. Zhai, K.L. Lin, H.B. Pan, W. Lu, J. Chang, Synthesis, in vitro hydroxyapatite forming ability, and cytocompatibility of strontium silicate powders, J. Biomed. Mater. Res. Part B-Applied Biomater. 93B (2010) 252-257.

[56] Y. Zhu, Y. Ouyang, Y. Chang, C. Luo, J. Xu, C. Zhang, et al., Evaluation of the proliferation and differentiation behaviors of mesenchymal stem cells with partially converted borate glass containing different amounts of strontium in vitro., Mol. Med. Rep. 7 (2013) 1129-36.

[57] M.D. O'Donnell, P.L. Candarlioglu, C.A. Miller, E. Gentleman, M.M. Stevens, Materials characterisation and cytotoxic assessment of strontium-substituted bioactive glasses for bone regeneration, J. Mater. Chem. 20 (2010) 8934.

[58] A.M.C. Barradas, H.A.M. Fernandes, N. Groen, Y.C. Chai, J. Schrooten, J. van de Peppel, et al., A calcium-induced signaling cascade leading to osteogenic differentiation of human bone marrow-derived mesenchymal stromal cells., Biomaterials. 33 (2012) 3205-15.

[59] F. Yang, D. Yang, J. Tu, Q. Zheng, L. Cai, L. Wang, Strontium enhances osteogenic differentiation of mesenchymal stem cells and in vivo bone formation by activating Wnt/catenin signaling., Stem Cells. 29 (2011) 981-91.

[60] M.M. Stevens, J.H. George, Exploring and engineering the cell surface interface., Science. 310 (2005) 1135-8.

[61] L. Bacakova, E. Filova, M. Parizek, T. Ruml, V. Svorcik, Modulation of cell adhesion, proliferation and differentiation on materials designed for body implants., Biotechnol. Adv. 29 (2011) 739-67. 